Available online at_www.iponlinejournal.com

\title{
Prescription pattern, safety and prevalence of resistance of antimicrobial drugs in MICU of IGIMS, Patna: An observational and prospective study
}

\author{
Shambhu Kumar Yadav ${ }^{1}$, Saajid Hameed ${ }^{2 *}$, Manish Kumar ${ }^{3}$, Hitesh Mishra ${ }^{4}$, Lalit Mohan ${ }^{5}$, Harihar Dikshit $^{6}$ \\ ${ }^{1,2}$ Senior Resident, ${ }^{3}$ Associate Professor, ${ }^{4,5}$ Additional Professor, ${ }^{6}$ Professor and Head, Dept. of Pharmacology, Indira Gandhi Institute of \\ Medical Sciences, Patna, Bihar
}

\begin{abstract}
Objective: Due to limited availability of newer antibiotics to treat emerging multidrug-resistant species of pathogen, there is an urgent need for highlighting the misuse of antibiotics and taking appropriate measures to promote rational antibiotic prescription.

This study was designed to know the antibiotic prescription patterns in MICU, the prevalence of antibiotic resistance, the effectiveness of empirical antibiotic therapy and safety and tolerability of the antibiotics prescribed.

Materials and Methods: This study was an observational and prospective study. 100 consecutive prescriptions were collected from MICU, IGIMS, Patna from January 2019 to June 2019. All antibiotics listed on first prescription slip was noted and their dosage schedule, route of administration, date of discontinuation, generic name and related laboratory investigations were also recorded.

Result: 723 drugs were prescribed out of which 244 were antibiotics. 3rd generation cephalosporins (118 prescription/48.36 $\%$ ) were most frequently prescribed followed by Amoxicillin + Clavulanate (40 prescriptions/16.39\%). Prevalence of resistance was most in cephalosporins (6\%) followed by Amoxicillin + Clavulanate (5\%). Approx. 27.5\% failure of treatment was found in patients receiving empirical antibiotic therapy. Percentage of suspected ADRs was mostly found in linezolid $(33.33 \%)$ followed by Ceftriaxone $(16.66 \%)$.

Conclusion: Antibiotics are overprescribed in our ICUs and this is increasing the burden of unnecessary adverse effect, resistance and treatment costs. At the time of admission, patients with poor prognosis and older age are prescribed more antibiotics. Antibiotics stewardship programs should be promoted and regulation of antibiotic utilization, proper use of guidelines and proper surveillance should be ensured by responsible authorities.
\end{abstract}

Keywords: Antibiotics, ICU, Prescriptions, Resistance, Safety \& tolerability.

\section{Introduction}

Discovery of antibiotics has brought a drastic change in treatment of infectious diseases. But in present era; misuse, overuse and emerging resistance continue to be threat for the management of infection. In intensive care unit, mostly empirical therapy is given. In ICU setting before obtaining culture \& sensitivity reports, patients are frequently treated with more than one antibiotic. And most of these are broad spectrum antibiotics. As compared to patients of general wards, patients of ICU are in serious condition and undergo more invasive procedures. So, they have high risk of multidrug resistant pathogenic infection. The prescriptions of ICUs are generally more empirical leading to misuse and overuse of antibiotics. Besides increasing treatment cost, overuse of antibiotics exposes patients to unnecessary side effects and also increases the burden of antibiotic resistance. ${ }^{1-3}$ Due to limited availability of newer antibiotics to treat emerging multidrug-resistant species of pathogens ${ }^{4}$, there is an urgent need for highlighting the misuse of antibiotics and taking appropriate measures to promote rational antibiotic prescription. ${ }^{1,2}$ Some of the previous studies suggest that reducing the use of antibiotics may be associated with similar or improved outcomes and reduced adverse effects. ${ }^{5-8}$

Hence, in this study we aimed to observe the antibiotic prescription patterns in MICU, the prevalence of antibiotics prescribed and antibiotic resistance, the effectiveness of empirical antibiotic therapy, safety and tolerability through prospectively observing the prescription given in MICU.

\section{Materials and Methods Study Site/Place}

Medical Intensive Care Unit (MICU) of Indira Gandhi Institute of Medical Sciences, Patna

\section{Study duration}

6 Months from January 2019 to June 2019

Study design

Observational and prospective study

\section{Inclusion criteria}

1. Age $\geq 18$ years and all gender

2. At least one antibiotic in prescription

*Corresponding Author: Saajid Hameed, Dept. of Pharmacology, Indira Gandhi Institute of Medical Sciences, Patna, Bihar, India Email: saajid36@gmail.com

http://doi.org/10.18231/j.ijcaap.2019.023 


\section{Exclusion criteria}

Pregnant and Breastfeeding women

100 Prescriptions of the patients admitted in medical ICU were collected. They were followed up and their IPD files were observed. Demographic variables on patients such as name, sex, age, clinical diagnosis and the APACHE II score (Acute Physiology And Chronic Health Evaluation score to assess the severity of illness) were recorded. APACHE II score was calculated from the calculator provided in Medscape website ${ }^{9}$. All antibiotics listed on first prescription slip was noted and their dosage schedule, route of administration, date of discontinuation, generic name and related laboratory investigations were also recorded.

Culture reports of patients were collected, and sensitivity and resistance patterns of Antimicrobials were recorded. Suspected Adverse Drug Reactions (ADRs) were also noted.

\section{Results}

Table 1: Demographic data and patient characteristics

\begin{tabular}{|c|c|c|}
\hline Variable & Number $(n=100)$ & Percentage \\
\hline \multicolumn{3}{|l|}{ Gender } \\
\hline Male & 65 & 65 \\
\hline Female & 35 & 35 \\
\hline \multicolumn{3}{|c|}{ Age Distribution } \\
\hline $15-30$ & 25 & 25 \\
\hline $31-45$ & 14 & 14 \\
\hline $46-60$ & 33 & 33 \\
\hline $61-75$ & 20 & 20 \\
\hline$>75$ & 8 & 8 \\
\hline \multicolumn{3}{|c|}{ Apache II Score } \\
\hline $0-9$ & 22 & 22 \\
\hline $10-19$ & 46 & 46 \\
\hline $20-29$ & 24 & 24 \\
\hline$>29$ & 8 & 8 \\
\hline \multicolumn{3}{|c|}{ Drugs Prescribed } \\
\hline $1-5$ & 45 & 45 \\
\hline $6-10$ & 48 & 48 \\
\hline$>10$ & 7 & 7 \\
\hline \multicolumn{3}{|c|}{ Antibiotics Prescribed } \\
\hline 0 & 5 & 5 \\
\hline $1-2$ & 70 & 70 \\
\hline $3-4$ & 21 & 21 \\
\hline$>5$ & 4 & 4 \\
\hline \multicolumn{3}{|c|}{ Length of ICU Stay } \\
\hline $1-5$ & 58 & 58 \\
\hline $6-10$ & 32 & 32 \\
\hline $11-15$ & 8 & 8 \\
\hline$>15$ & 2 & 2 \\
\hline \multicolumn{3}{|c|}{ Outcome from ICU } \\
\hline Discharged & 60 & 60 \\
\hline Expired & 40 & 40 \\
\hline
\end{tabular}

Table 2: Pattern of antibiotic prescribed

\begin{tabular}{|l|c|c|c|}
\hline \multicolumn{1}{|c|}{ Diagnosis } & Patients (n) & Total Drugs & Total Antibiotics \\
\hline Sepsis/SIRS (Systemic Inflammatory Response Syndrome) & 30 & 223 & 103 \\
\hline Surgical & 15 & 76 & 35 \\
\hline Dengue/DHS (Dengue Haemorrhagic Syndrome) & 11 & 75 & 18 \\
\hline Trauma/Poisoning & 11 & 61 & 19 \\
\hline Burns & 2 & 8 & 4 \\
\hline Others & 31 & 280 & 65 \\
\hline
\end{tabular}




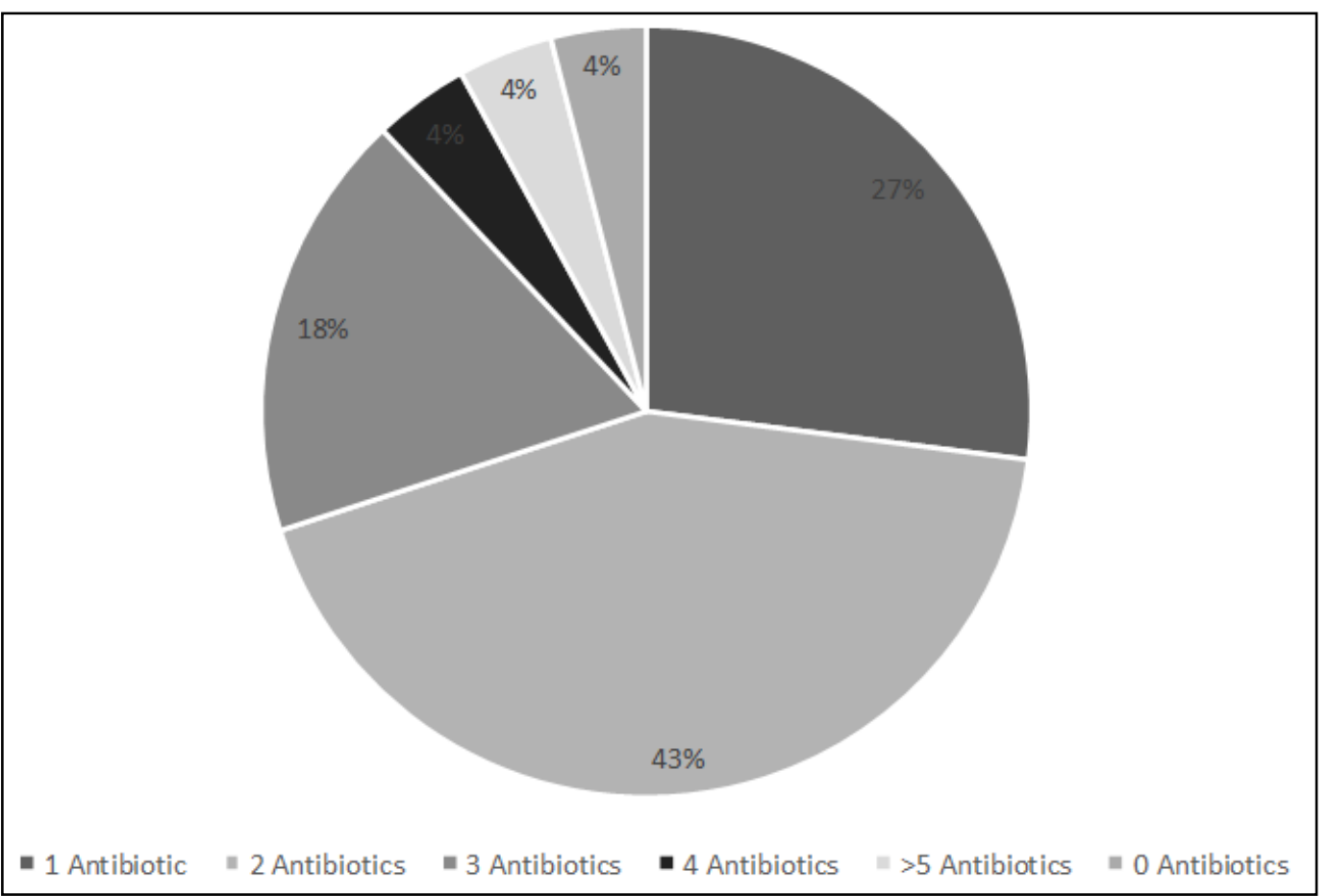

Fig. 1: Distribution of patients according to number of antibiotics

Table 3: Univariate analysis of the factors affecting the number of antibiotics prescribed

\begin{tabular}{|c|c|c|}
\hline Variables & $\mathbf{1 - 2}$ Antibiotics $(\mathbf{n}=\mathbf{7 0})$ & $>/=3$ Antibiotics $(\mathbf{n}=\mathbf{3 0})$ \\
\hline Age (Years) & & $12 / 14$ \\
\hline$\leq 45 />45$ & $24 / 46$ & $14 / 12$ \\
\hline Gender & $48 / 22$ & $13 / 12$ \\
\hline Male/Female & & 13 \\
\hline Total ICU Days & $42 / 28$ & \\
\hline$\leq 5$ days/ $>$ 5 Days & 24 & 4 \\
\hline Mortality (Overall) & & 07 \\
\hline Mortality Based on Apache Id & 6 & 2 \\
\hline $1-14$ & 16 & \\
\hline $15-30$ & 2 & \\
\hline$\geq 31$ & & \\
\hline
\end{tabular}

Table 4: Most frequently used antibiotics and prevalence of their resistance

\begin{tabular}{|l|c|c|c|c|}
\hline Name & $\begin{array}{l}\text { Number } \\
\text { prescriptions }\end{array}$ & $\begin{array}{l}\text { Treatment } \\
\text { failure }\end{array}$ & Death & $\begin{array}{l}\text { Number of culture } \\
\text { reports } \\
\text { resistance }\end{array}$ \\
\hline Ceftriaxonewing \\
\hline Cefotaxime & 60 & 15 & 3 & 06 \\
\hline Amoxycillin/Clavulanate & 58 & 12 & 2 & 06 \\
\hline Levofloxacin & 40 & 8 & 2 & 05 \\
\hline Metronidazole & 30 & 5 & 1 & 04 \\
\hline Amikacin & 28 & 6 & 3 & 02 \\
\hline Gentamicin & 27 & 3 & 2 & 03 \\
\hline Imipenem & 20 & 2 & 1 & 03 \\
\hline Meropenem & 06 & 0 & 0 & 01 \\
\hline Linezolid & 04 & 1 & 1 & 01 \\
\hline Clindamycin & 03 & 1 & 1 & 01 \\
\hline
\end{tabular}


Table 5: Effectiveness of empirical therapy

\begin{tabular}{|l|c|c|c|c|}
\hline \multicolumn{1}{|c|}{ Name of antibiotic } & $\begin{array}{l}\text { Number of Prescriptions } \\
\text { In Which the Antibiotic } \\
\text { Was Given Before } \\
\text { Culture Reports }\end{array}$ & $\begin{array}{l}\text { Treatment } \\
\text { Failure }\end{array}$ & $\begin{array}{l}\text { Number of Prescriptions } \\
\text { In Which the Antibiotic } \\
\text { Was Given After Culture } \\
\text { Reports }\end{array}$ & $\begin{array}{c}\text { Treatment } \\
\text { Failure }\end{array}$ \\
\hline Ceftriaxone & 51 & 14 & 09 & 01 \\
\hline Cefotaxime & 49 & 11 & 09 & 01 \\
\hline Amoxycillin/Clavulanate & 34 & 7 & 06 & 01 \\
\hline Levofloxacin & 26 & 5 & 04 & 00 \\
\hline Metronidazole & 24 & 5 & 04 & 01 \\
\hline Amikacin & 23 & 3 & 04 & 00 \\
\hline Gentamicin & 17 & 2 & 03 & 00 \\
\hline Imipenem & 05 & 0 & 01 & 00 \\
\hline Meropenem & 02 & 1 & 02 & 00 \\
\hline Linezolid & 02 & 1 & 01 & 00 \\
\hline Clindamycin & 02 & 00 & 00 \\
\hline
\end{tabular}

Table 6: Safety \& Tolerability

\begin{tabular}{|l|c|c|c|}
\hline \multicolumn{1}{|c|}{ Name } & $\begin{array}{c}\text { Total Number of } \\
\text { Prescriptions }\end{array}$ & $\begin{array}{c}\text { Number of Suspected } \\
\text { ADRs }\end{array}$ & $\begin{array}{c}\text { Percentage of } \\
\text { Suspected ADR }\end{array}$ \\
\hline Ceftriaxone & 60 & 10 & 16.66 \\
\hline Cefotaxime & 58 & 08 & 13.8 \\
\hline Amoxycillin/Clavulanate & 40 & 02 & 05 \\
\hline Levofloxacin & 30 & 03 & 10 \\
\hline Metronidazole & 28 & 02 & 7.14 \\
\hline Amikacin & 27 & 03 & 11.11 \\
\hline Gentamicin & 20 & 02 & 10 \\
\hline Imipenem & 06 & 00 & 00 \\
\hline Meropenem & 04 & 00 & 00 \\
\hline Linezolid & 03 & 01 & 33.33 \\
\hline Clindamycin & 02 & 00 & 00 \\
\hline
\end{tabular}

\section{Discussion}

A total of 100 prescriptions was collected over 6 months from MICU of IGIMS, Patna. Most of the patients admitted were middle aged (46-60 years). Median APACHE II score of our sample was 14. Most of the patients were from medical speciality and most of them were having sepsis syndrome (30 Patients). The demographic data and patients' characteristics are given in Table 1.

723 drugs were prescribed of which 244 were antibiotics. It means 33.74 of the total drugs prescribed were antibiotics. 85 patients were prescribed antibiotic at the time of admission into ICU. Distribution of patients according to number of patients is shown in figure 1.

Various clinical factors influencing number of drugs and antibiotics prescribed such as diagnosis at time of admission and APACHE II score were studied. Most number of antibiotics were prescribed to patients with sepsis syndrome [Table 2]. More number of drugs were prescribed to patients having higher APACHE II score (>15) but the average number of antibiotics prescribed were similar. Poor outcomes were seen more in patients prescribed more antibiotics. Patients who were prescribed more than 3 antibiotics and had APACHE II scores between 15 and 30 had significantly more risk of mortality $(\mathrm{P}=0.0289)$.
Ceftriaxone was most prescribed followed by cefotaxime. However, in culture reports of most of the patients showed resistant to ceftriaxone and cefotaxime.

Most of the patients in our study were discharged from the ICU after recovery (60 patients) while 40 patients expired.

In Iran, a study on ICU drug use pattern,${ }^{10}$ the mean age of patients was 50 years and mean period of stay was 6 days and the mean period of stay in surgical patients was higher. A similar study was carried out by Bergmans et al, ${ }^{11}$ the mean period of stay was 7 days and the diagnosis most frequent found was skin and soft tissue infections. Their APACHE II scores were also like our study.

The average number of drugs prescribed to patients is an important factor for a prescription audit. To decrease the burden of bacterial resistance, hospital costs, adverse effects and risk of drug interactions number of drugs should be kept as low as possible. ${ }^{12}$ A mean of 6.19 drugs were prescribed per patient in our study and it is comparable to other studies in which we can find the range of drugs prescribed between 5.1 to $12 .^{13-14}$ varying on the basis of type of patient population and the geographical location studied.

It was found in this study that many of the patients were prescribed antibiotics at the time of admission 
(approximately 95\%). Biswal et $\mathrm{al}^{15}$ found that approximately $62 \%$ patients were prescribed antibiotics in ICU of tertiary care hospital of northern India while shrikala et $\mathrm{al}^{16}$ found $64 \%$ prescriptions containing antibiotics in ICU. 58\%-61\% use of antibiotics were reported from studies in Europe and from other countries it was found to be 60$75 \% .{ }^{17-19}$ In a survey done in Australia and New Zealand on prescribing pattern of antibiotics in ICUs, it was found that 656 antibiotics were prescribed in 120 days study period. ${ }^{20}$

Antibiotics were chosen at the first hour of treatment in patients of severe sepsis and this is identified as an important factor for clinical outcomes. Capp et al has done a study on 1400 patients of ICU and found that $82 \%$ patients received appropriate antibiotic therapy. ${ }^{21}$ They also found that following set guidelines for community and healthcare associated infection was $100 \%$ sensitive tool for selecting patients having infections caused by more resistant organisms.

In our study $3^{\text {rd }}$ generation cephalosporins (118 prescription) were most frequently prescribed followed by Amoxicillin/Clavulanate (40 prescriptions). In other studies, conducted in India, cefaperazone and piperacillin were the most prescribed antibiotics. ${ }^{16}$

We found that patients with poor prognosis were prescribed more number of antibiotics and this could be the reason for overuse of antibiotics in ICU. Our study was done prospectively and the relation between prescription of antibiotics and age, sex, gender, prognosis of the patients was studied. The data on utilization of antimicrobial in ICU is limited and this data is important in health care system of India because most of the people hardly bear the cost of treatment and there is lack of health insurance and government fund. So, more studies are required to add up to this data.

The result of this study shows that there are many areas that need our attention. Strict antibiotic restriction policy and implantation of protocol for rational use of antimicrobials are needed to ensure appropriate use of antimicrobials. Other studies have also shown that better health care services can be provided to patients at affordable cost by implementing policies for rational use of antibiotics. $^{22,23}$ Similarly decrease in consumption of antibiotics has been observed with restricted authorization to prescribe antibiotics, consultation with infectious disease specialist and implementation of local antibiotic management programs. ${ }^{24}$

National and state government should have their antibiotic utilisation policies to ensure appropriate use of antibiotics. Every hospital should have their own antibiotic utilisation policies based on disease present in their localities. It must be ensured that every prescriber know recent guidelines and clinical pathways. Promoting antibiotic stewardship program will aid in resolving the emerging problems of overprescribing and developing resistance.

\section{Conclusion}

Antibiotics are overprescribed in our ICUs and this is increasing the burden of unnecessary adverse effect, resistance and treatment costs. At the time of admission, patients with poor prognosis and older age are prescribed more antibiotics. Antibiotics stewardship programs should be promoted. And regulation of antibiotic utilization, proper use of guidelines and proper surveillance should be ensured by responsible authorities.

\section{Source of Funding}

None.

\section{Conflict of Interest}

None.

\section{References}

1. Esposito S, Leone S. Antimicrobial treatment for intensive care unit (ICU) infections including the role of the infectious diseases specialist. Int J Antimicrob Agents 2007;29:494-500. [PubMed: 17346938]

2. Lockhart SR, Abramson MA, Beekman SE, Gallagher G, Riedel SR, Diekma DJ, et al. Antimicrobial resistance among gram-negative bacilli as causes of infections in intensive care unit patients in the United States between 1993 and 2004. $J$ Clin Microbiol 2007;45:3352-9. [PMCID: PMC2045364] [PubMed: 17715376]

3. Weber RJ, Kane SL, Oriolo VA, Saul M, Skledar SJ, Dasta JF et al. Impact of intensive care drug costs: A descriptive analysis, with recommendations for optimizing ICU pharmacotherapy. Crit Care Med 2003;31:17-24.

4. Paterson DL, Rogers BA. How Soon Is Now? The urgent need for randomized, controlled trials evaluating treatment of multidrug-resistant bacterial infection. Clin Infect Dis 2010;51:1245-7. [PubMed: 20973726]

5. Fagon JY, Chastre J, Wolff M, et al. Invasive and noninvasive strategies for management of suspected ventilator-associated pneumonia. A randomized trial. Ann Intern Med 2000;132:621-30. 15.

6. Aarts MA, Brun-Buisson C, Cook DJ, et al. Antibiotic management of suspected nosocomial ICU-acquired infection: does prolonged empiric therapy improve outcome? Intensive Care Med 2007;33:1369-78.

7. Blanco J, Muriel-Bombín A, Sagredo V, Grupo de Estudios y Análisis en Cuidados Intensivos. Incidence, organ dysfunction and mortality in severe sepsis: a Spanish multicentre study. Crit Care 2008;12:R158.

8. Kett DH, Cano E, Quartin AA, et al; Improving Medicine through Pathway Assessment of Critical Therapy of HospitalAcquired Pneumonia (IMPACTHAP) Investigators. Implementation of guidelines for management of possible multidrug-resistant pneumonia in intensive care: an observational, multicentre cohort study. Lancet Infect Dis 2011;11:181-9.

9. https://reference.medscape.com/calculator/apache-ii-scoringsystem

10. Tavallaee M, Fahimi F, Kiani S. Drug-use patterns in an intensive care unit of a hospital in Iran: An observational prospective study. Int J Pharm Pract 2010;18:370-6. [PubMed: 21054598]

11. Bergmans DCJJ, Bontena MJM, Gaillard CA, van Tiel FH, Van Der Geesta S, De Leeuwa PW, et al. Indications for antibiotic use in ICU patients: A one-year prospective 
surveillance. J Antimicrob Chemother 1997;39:527-35. [PubMed: 9145828]

12. Stratton $\mathrm{CW}, 4$ th, Ratner H, Johnston PE, Schaffner W. Focused microbiological surveillance by specific hospital unit: Practical application and clinical utility. Clin Ther 1993;15(Suppl A):12-20. [PubMed: 8513456]

13. Shankar PR, Partha P, Dubey AK, Mishra P, Deshpande VY. Intensive care unit drug utilization in a teaching hospital in Nepal. Kathmandu Univ Med J (KUMJ) 2005;3:130-7. [PubMed: 16415608]

14. Smythe MA, Melendy S, Jahns B, Dmuchowski C. An exploratory analysis of medication utilization in a medical intensive care unit. Crit Care Med 1993;21:1319-23. [PubMed: 8370295]

15. Biswal S, Mishra P, Malhotra S, Puri GD, Pandhi P. Drug Utilization Pattern in the Intensive Care Unit of a Tertiary Care Hospital. J Clin Pharmacol 2006;46:945-51. [PubMed: 16855079]

16. Shrikala B, Kranthi K, Nafisa A prospective study on evaluation of antibiotic prescription practices in an intensive care unit of a tertiary care hospital. J Clin Diag Res 2010;4:3387-91.

17. Erbay A, Bodur H, Akinci E, Colpan A. Evaluation of antibiotic use in intensive care units of a tertiary care hospital in Turkey. J Hosp Infect 2005;59:53-61. [PubMed: 15571854]

18. Hanssens Y, Ismaeil BB, Kamha AA, Elshafie SS, Adheir FS, Saleh TM, et al. Antibiotic prescription pattern in a medical intensive care unit in Qatar. Saudi Med J 2005;26:1269-76. [PubMed: 16127527]

19. Hartmann B, Junger A, Brammen D, Röhrig R, Klasen J, Quinzio L, et al. Review of antibiotic drug use in a surgical
ICU: management with a patient data management system for additional outcome analysis in patients staying more than 24 hours. Clin Ther 2004;26:915-24. [PubMed: 15262462]

20. Dulhunty JM, Webb SA, Paterson DL, Bellomo R, Myburgh J, Roberts JA, et al. A survey of antibiotic prescribing practices in Australian and New Zealand intensive care units. Crit Care Resusc 2010;12:162 -70. [PubMed: 21261573]

21. Capp R, Chang Y, Brown DF. Effective Antibiotic Treatment Prescribed by Emergency Physicians in Patients Admitted to the Intensive Care Unit with Severe Sepsis or Septic Shock: Where is the Gap? J Emerg Med 2011

22. Blanc P, Von Elm BE, Geissler A, Granier I, Boussuges A, Durand Gasselin J. Economic impact of a rational use of antibiotics in intensive care. Intensive Care Med 1999;25:1407-12. [PubMed: 10660849]

23. Thursky KA, Buising KL, Bak N, Macgregor L, Street AC, Macintyre CR, et al. Reduction of broadspectrum antibiotic use with computerized decision support in an intensive care unit. Int J Qual Health Care 2006;18:224-31. [PubMed: 16415039]

24. Peto Z, Benko R, Matuz M, Csullog E, Molnar A, Hajdu E et al. Results of a local antibiotic management program on antibiotic use in a tertiary intensive care unit in Hungary. Infect 2008;36:560-4. [PubMed: 19011742]

How to cite this article: Yadav SK, Hameed S, Kumar M, Mishra H, Mohan L, Dikshit H. Prescription pattern, safety and prevalence of resistance of antimicrobial drugs in MICU of IGIMS, Patna: An observational and prospective study. Int J Comprehensive Adv Pharmacol 2019;4(3):110-5. 